\title{
Automation of hydrological drought typology to study drought propagation in a tropical catchment
}

\author{
Beatriz Quesada-Montano ${ }^{1}$, Anne F. Van Loon ${ }^{2}$, Hugo Hidalgo ${ }^{3}$, Ida Westerberg ${ }^{4}$, \\ Christian Birkel $^{5}$, and Fredrik Wetterhall ${ }^{6}$ \\ ${ }^{1}$ Uppsala University \\ ${ }^{2}$ Vrije Universiteit Amsterdam \\ ${ }^{3}$ Universidad de Costa Rica \\ ${ }^{4}$ IVL Swedish Environmental Research Institute \\ ${ }^{5}$ University of Costa Rica \\ ${ }^{6}$ European Centre For Medium Range Weather Forecasts
}

November 23, 2021

\begin{abstract}
Understanding how droughts propagate through the hydrological cycle from precipitation to streamflow and groundwater is important for improving water and risk management policies. At the catchment scale, the analysis of drought propagation and classification into drought types is usually done manually, which can be time consuming and difficult to replicate. Here, we developed an automated, objective procedure for classification of different drought types with the aim to study drought propagation in the tropics. The method was applied to the Savegre catchment in Costa Rica as a proof-of-concept. We first confirmed that drought events in the catchment could be classified into the process-based typology from the literature: classical rainfall deficit drought, wet-to-dry season drought, and composite drought. The automation algorithm was able to replicate the classification obtained with the manual typology with the exception of two events, and thus it is a development towards objective and time efficient hydrological drought analysis in tropical catchments. Most of the detected hydrological droughts ( $80 \%$ and $76 \%$ of all river discharge and baseflow droughts, respectively) were classical rainfall deficit droughts, which suggests that climate plays a more important role in drought development than catchment characteristics in this catchment. However, the importance of catchment characteristics was revealed by the presence of severe composite drought events and by the attenuation of significant precipitation droughts.
\end{abstract}

\section{Hosted file}

Manuscript_BQM.docx available at https://authorea.com/users/447664/articles/546607automation-of-hydrological-drought-typology-to-study-drought-propagation-in-a-tropicalcatchment 

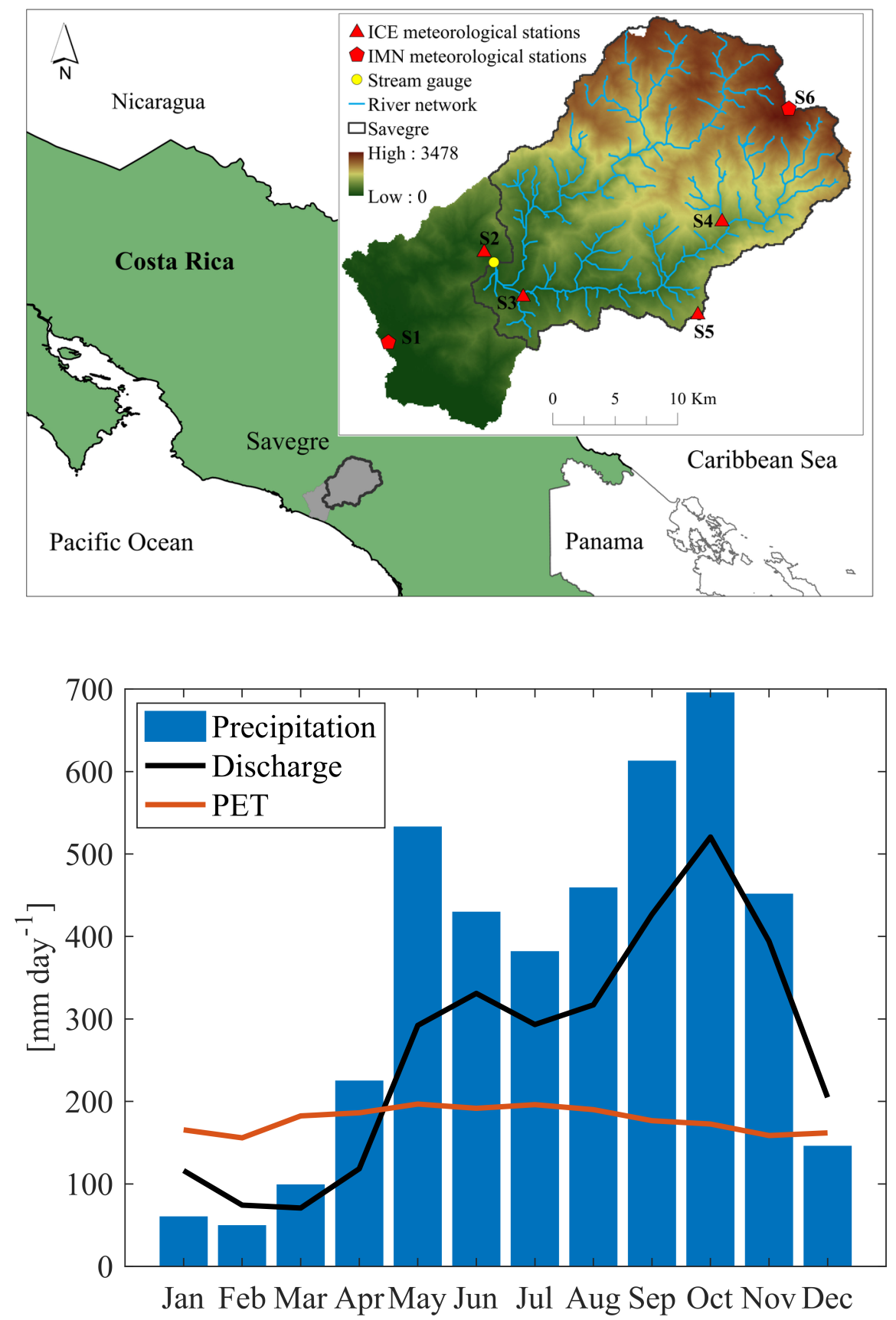


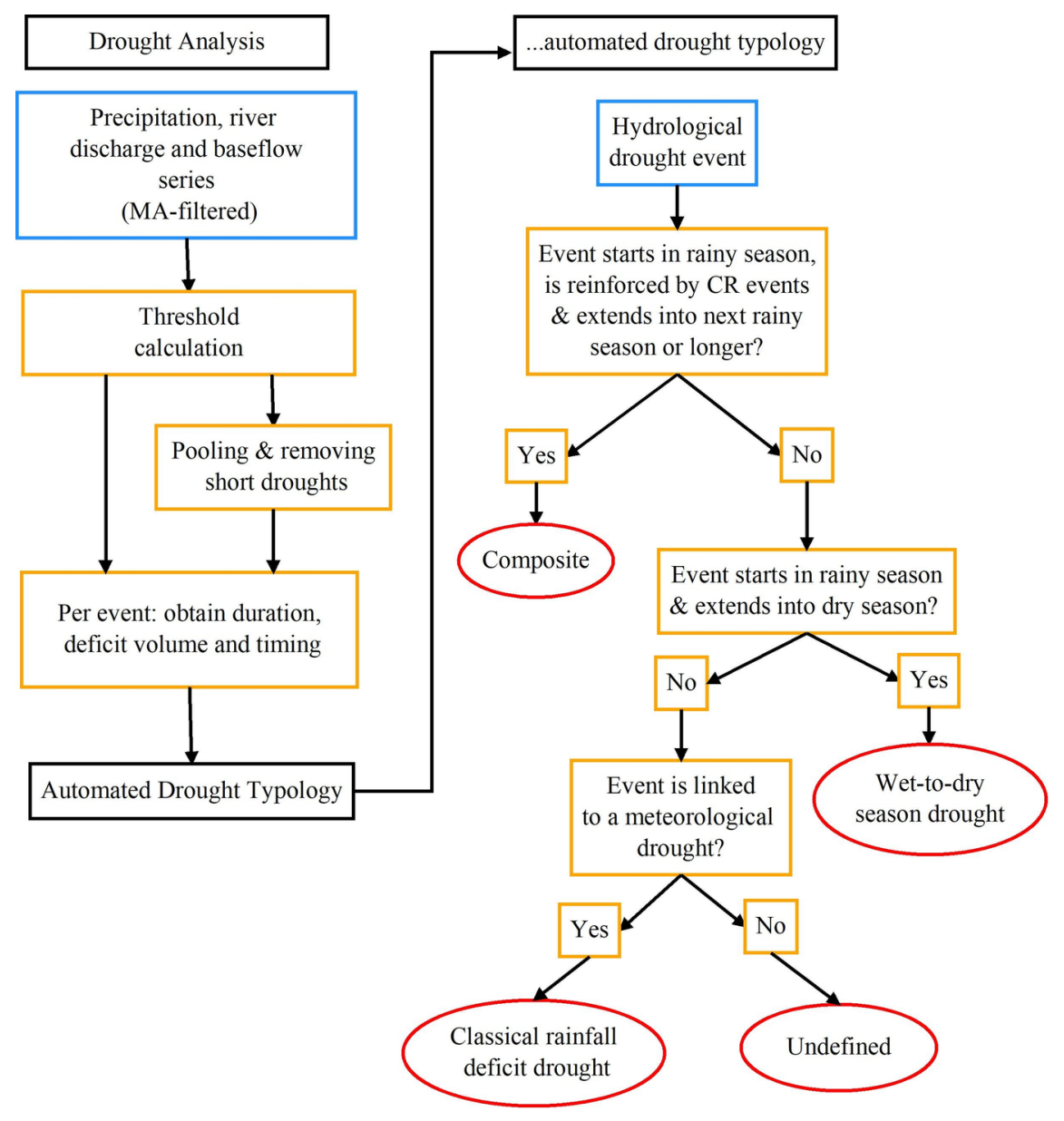



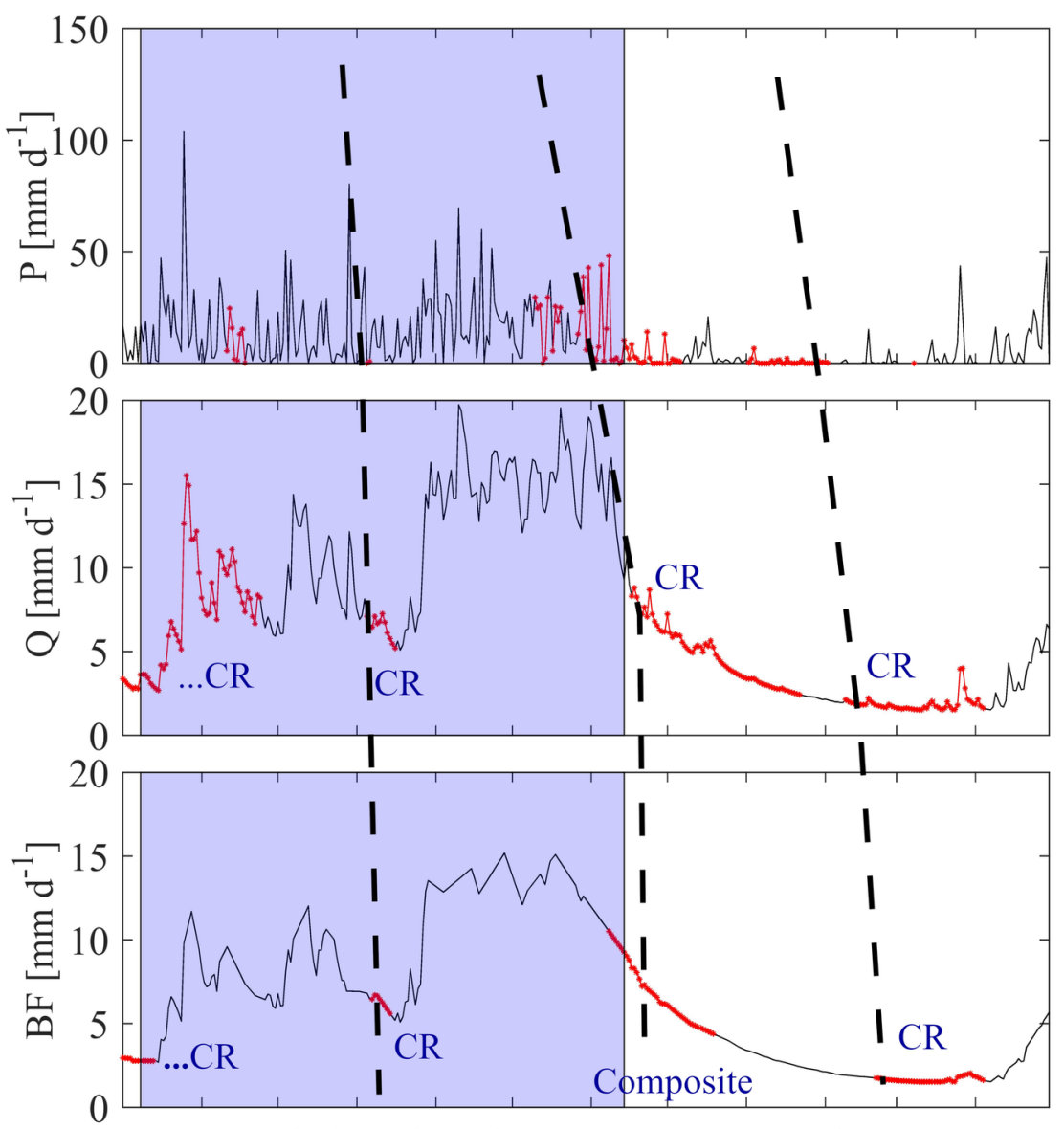

May Jun Jul Aug Sep Oct Nov Dec Jan Feb Mar Apr Month for period 2002-2003 


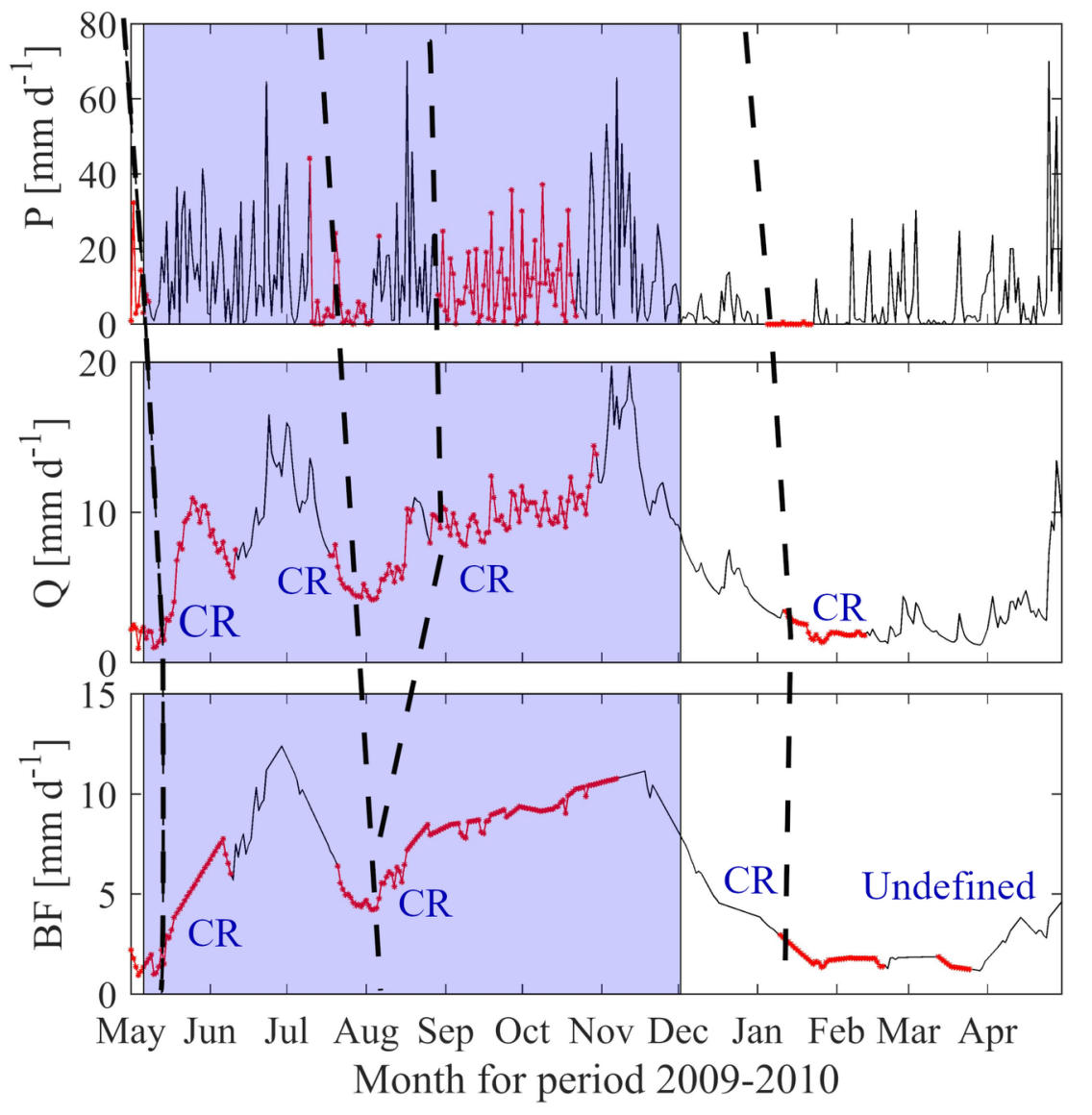



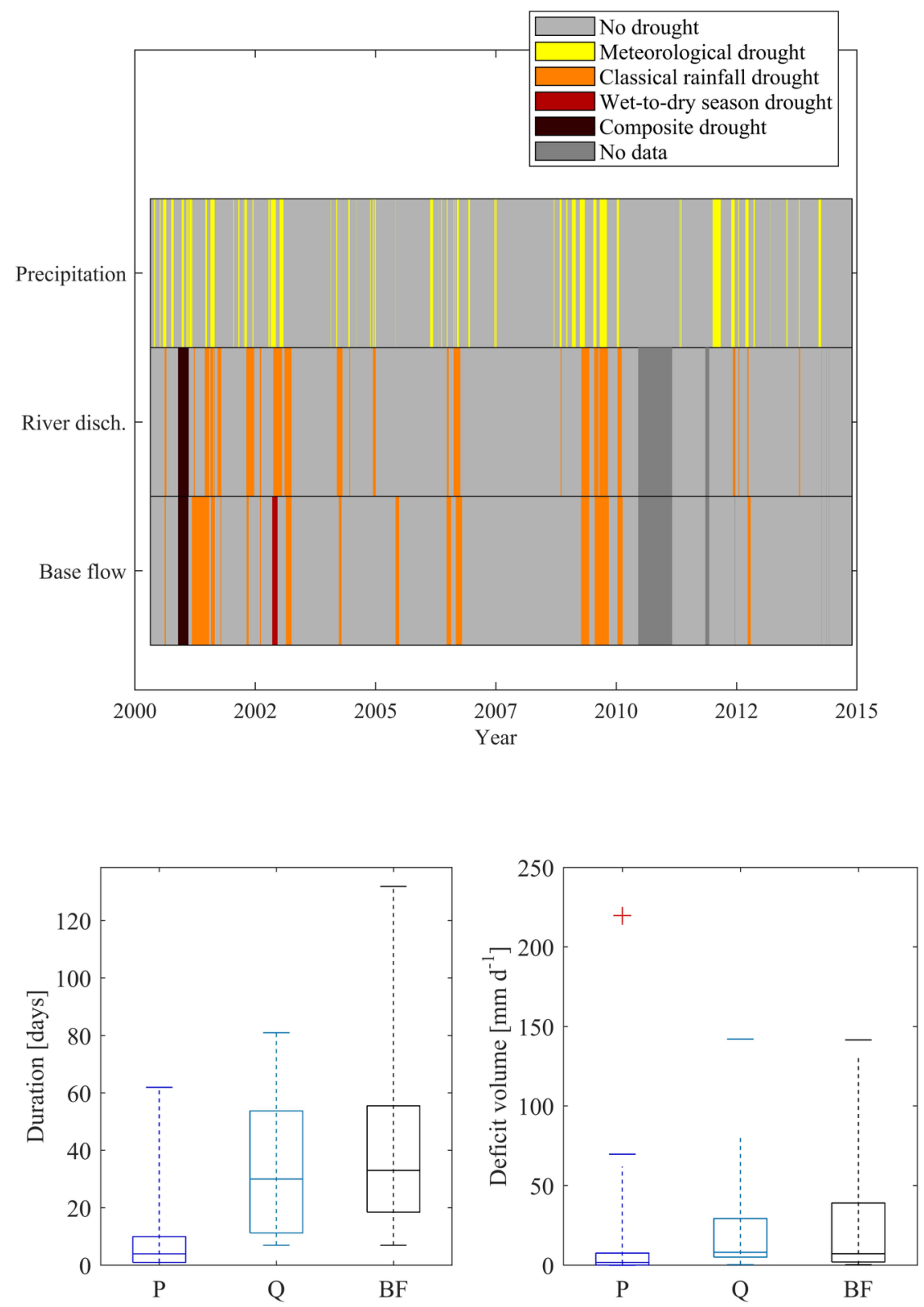

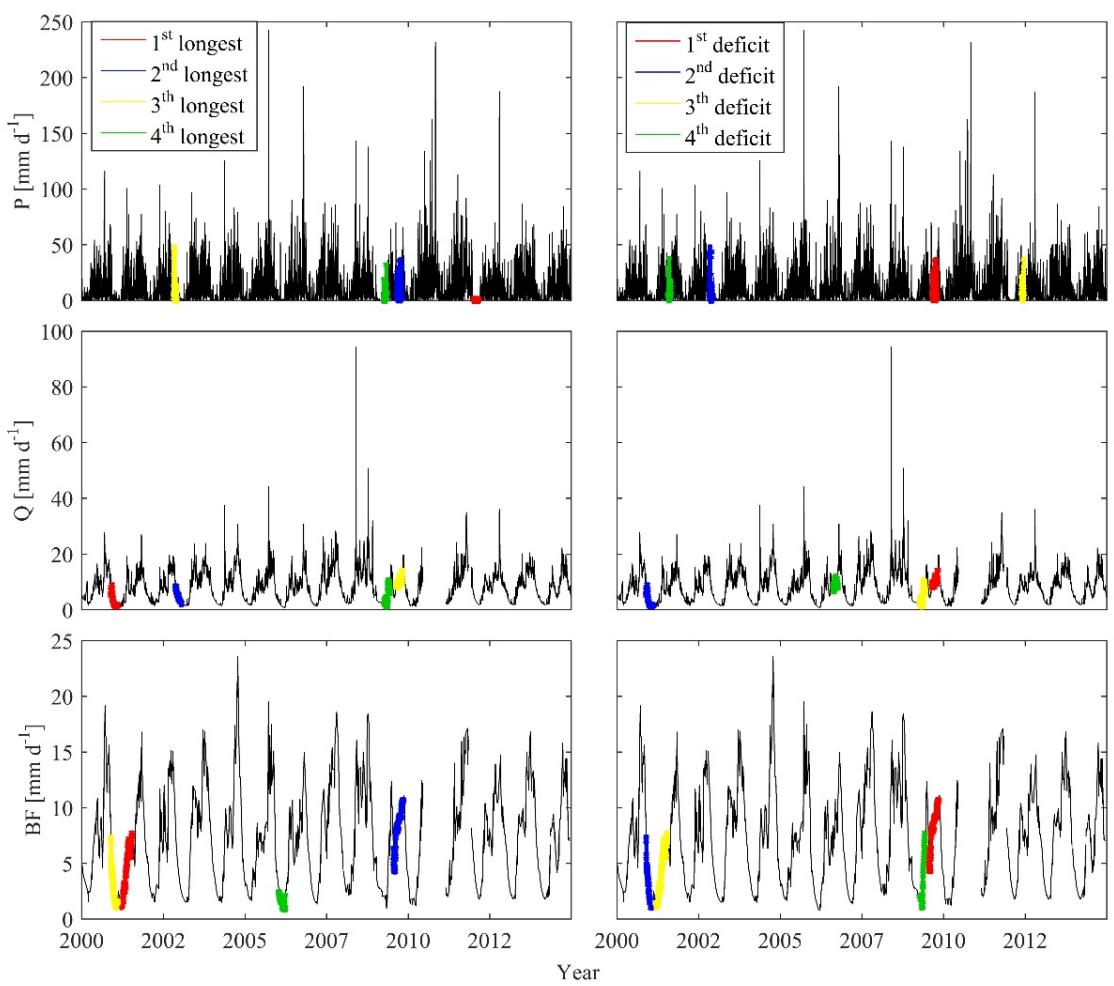

\section{Hosted file}

Table 1.docx available at https://authorea.com/users/447664/articles/546607-automation-ofhydrological-drought-typology-to-study-drought-propagation-in-a-tropical-catchment

\section{Hosted file}

Table 2.docx available at https://authorea.com/users/447664/articles/546607-automation-ofhydrological-drought-typology-to-study-drought-propagation-in-a-tropical-catchment 